\title{
Impact of COVID-19 on liver function: results from an internal medicine unit in Northern Italy
}

\author{
Marco Vincenzo Lenti ${ }^{1} \cdot$ Federica Borrelli de Andreis ${ }^{1} \cdot$ Ivan Pellegrino $^{1} \cdot$ Catherine Klersy $^{2} \cdot$ Stefania Merli $^{1}$. \\ Emanuela Miceli ${ }^{1}$. Nicola Aronico ${ }^{1}$. Caterina Mengoli ${ }^{1} \cdot$ Michele Di Stefano $^{1}$ - Sara Cococcia ${ }^{1}$. \\ Giovanni Santacroce $^{1}$ - Simone Soriano ${ }^{1} \cdot$ Federica Melazzini $^{1}$ - Mariangela Delliponti ${ }^{1} \cdot$ Fausto Baldanti $^{3}$. \\ Antonio Triarico ${ }^{4}$. Gino Roberto Corazza ${ }^{1}$. Massimo Pinzani ${ }^{5}$. Antonio Di Sabatino ${ }^{1,6}$ (i) on behalf of the Internal \\ Medicine Covid-19 Team
}

Received: 27 May 2020 / Accepted: 27 June 2020 / Published online: 10 July 2020

(c) The Author(s) 2020

\begin{abstract}
Little is known regarding coronavirus disease 2019 (COVID-19) clinical spectrum in non-Asian populations. We herein describe the impact of COVID-19 on liver function in 100 COVID-19 consecutive patients (median age 70 years, range 25-97; 79 males) who were admitted to our internal medicine unit in March 2020. We retrospectively assessed liver function tests, taking into account demographic characteristics and clinical outcome. A patient was considered as having liver injury when alanine aminotransferase (ALT) was $>50 \mathrm{mU} / \mathrm{ml}$, gamma-glutamyl transpeptidase (GGT) $>50 \mathrm{mU} / \mathrm{ml}$, or total bilirubin $>1.1 \mathrm{mg} / \mathrm{dl}$. Spearman correlation coefficient for laboratory data and bivariable analysis for mortality and/or need for intensive care were assessed. A minority of patients (18.6\%) were obese, and most patients were non- or moderate-drinkers $(88.5 \%)$. Liver function tests were altered in $62.4 \%$ of patients, and improved during follow-up. None of the seven patients with known chronic liver disease had liver decompensation. Only one patient developed acute liver failure. In patients with altered liver function tests, $\mathrm{PaO}_{2} / \mathrm{FiO}_{2}<200$ was associated with greater mortality and need for intensive care (HR 2.34, 95\% CI 1.07-5.11, $p=0.033$ ). To conclude, a high prevalence of altered liver function tests was noticed in Italian patients with COVID-19, and this was associated with worse outcomes when developing severe acute respiratory distress syndrome.
\end{abstract}

Keywords Acute respiratory failure $\cdot$ Coronavirus $\cdot$ Hepatitis $\cdot$ Severe acute respiratory syndrome

\section{Abbreviations}

ALP

ALT

AST

BMI

CI COVID-19

Alkaline phosphatase

Alanine aminotransferase

Aspartate aminotransferase

Body mass index

Confidence interval

Coronavirus disease 2019

The members of the Internal Medicine Covid-19 Team are listed in Acknowledgements.

Joint co-first authors: Marco Vincenzo Lenti and Federica Borrelli de Andreis.

Electronic supplementary material The online version of this article (https://doi.org/10.1007/s11739-020-02425-w) contains supplementary material, which is available to authorized users.

Antonio Di Sabatino

a.disabatino@smatteo.pv.it

Extended author information available on the last page of the article

\author{
CRP C reactive protein \\ GGT Gamma-glutamyl transpeptidase \\ INR International normalised ratio \\ LDH Lactate dehydrogenase \\ SD Standard deviation \\ SARS-CoV-2 Severe acute respiratory syndrome corona- \\ virus 2 \\ STROBE STrengthening the Reporting of OBserva- \\ tional studies in Epidemiology
}

\section{Introduction}

Described for the first time in December 2019 in Wuhan (China) [1, 2], coronavirus disease 2019 (COVID-19), caused by severe acute respiratory syndrome coronavirus 2 (SARS-CoV-2, previously known as 2019-nCoV), has rapidly spread in late February 2020 in Northern Italy, and, to a lesser extent, in other parts of the country [3]. In a matter 
of weeks, as of 29th April 2020, the epidemic reached more than 200,000 individuals, with a high mortality rate, according to preliminary data released by the Italian Ministry of Health and the Italian Civil Protection [4]. Due to its worldwide spread, the World Health Organization declared COVID-19 a pandemic on 11th March 2020 [5].

COVID-19 pathogenesis, natural history, and optimal treatment still need to be elucidated, and little is known about its clinical spectrum in non-Asian populations. COVID-19 may be symptomless in many cases [6] and, when symptomatic, usually causes a flu-like syndrome (dry cough, sore throat, fever, diffuse muscle pain) that may be complicated by interstitial pneumonia with SARS and superimposed bacterial infections which may be fatal $[2,7-10]$. In fact, similar to SARS-CoV, SARS-CoV-2 is likely to bind to the angiotensin-converting enzyme 2 receptor, which is highly expressed in the respiratory tract, hence tissue damage mostly occurs in this site [11-13]. However, gastrointestinal involvement may precede the onset of respiratory symptoms, and patients may experience abdominal pain, nausea and diarrhoea during the course of the disease [14]. Also, in a substantial proportion of patients, especially those with a more severe disease, liver impairment may occur [15]. In previous Asian series, alanine aminotransferase (ALT) and aspartate aminotransferase (AST) elevation has been reported in roughly one-third of COVID-19 patients, and even a few cases of acute liver failure were observed [9, 15-20]. The mechanisms underlying liver impairment in COVID-19 are unknown, but they may be directly caused by the virus, or indirectly via other pathways (e.g., inflammation, hypoxia, medications). Also, nothing is known about liver impairment in non-Asian patients, and its clinical impact in these patients is poorly investigated.

Starting from these premises, the aim of this study was to describe the clinical characteristics of a cohort of patients with COVID-19 admitted to an internal medicine ward of an academic, tertiary referral hospital, with particular regard to liver impairment, and in relation to the clinical outcome. We also described the impact of COVID-19 in a sub-cohort of patients affected by chronic liver disease.

\section{Materials and methods}

In this single-centre, retrospective, observational study, we collected data from patients with Covid-19 who were admitted between 5th March and 28th March 2020 (last follow-up on 1st April 2020) to the internal medicine unit of San Matteo Hospital Foundation (Pavia, Italy), which comprises 76 beds usually occupied by patients referred from the local A\&E Department. During the SARSCoV-2 Italian epidemic, the internal medicine unit was transformed into a "COVID" ward [21] to overcome the dramatic increase of infected patients needing hospitalisation in Lombardy [22]. Demographic and clinical data of these patients were extracted and anonymised from the electronic hospital records onto a pre-defined spreadsheet. Relevant data included sex, age, smoking status, body mass index (BMI), alcohol intake, past medical history, and clinical description of COVID-19 at onset. We included all laboratory data that were requested as per clinical need, using the local laboratory reference level of normality as cut-off, at the time of admission (first timepoint). Liver function was considered impaired when ALT $>50 \mathrm{mU} / \mathrm{ml}$, and/or gamma-glutamyl transpeptidase $(\mathrm{GGT})>50 \mathrm{mU} / \mathrm{ml}$, and total bilirubin $>1.1 \mathrm{mg} / \mathrm{dl}$ (this latter when associated with altered transaminases and with no other causes of increase). Other relevant laboratory liver tests included serum cholinesterase, alkaline phosphatase (ALP), serum albumin, international normalised ratio (INR), serum glucose, and urine ketones. Lactate dehydrogenase (LDH) was assessed as an unspecific marker of cytolysis, while c reactive protein (CRP) was included as unspecific inflammatory marker. Neutrophilto-lymphocyte ratio was included as a marker of stress used in critically ill patients [23]. Arterial oxygen partial pressure to fractional inspired oxygen ratio $\left(\mathrm{PaO}_{2} / \mathrm{FiO}_{2}\right)$ was used for assessing the severity of respiratory failure. Diagnosis of COVID-19 was based on clinical grounds (flu-like symptoms, fever, tachypnoea, hypoxemia, presence of radiological interstitial pneumonia) and SARSCoV-2 detection through nasopharyngeal swab. More in depth, total nucleic acids (DNA/RNA) were extracted from samples $(200 \mu \mathrm{l})$ using the QIAsymphony ${ }^{\circledR}$ instrument with QIAsymphony ${ }^{\circledR}$ DSP Virus/Pathogen Midi Kit (Complex 400 protocol) following the manufacturer's instructions (QIAGEN, Qiagen, Hilden, Germany). Specific realtime PCR targeting RNA-dependent RNA polymerase and E genes were used to detect the presence of SARS-CoV-2 according to internationally recognised criteria [24, 25]. In a few patients with negative nasopharyngeal swab, but high clinical suspicious, diagnosis was made through bronchoalveolar lavage. Nasopharyngeal swab for ruling out other possible viral co-infections of the upper respiratory tract (i.e., influenza A and B, parainfluenza viruses, syncytial respiratory virus, rhinoviruses, adenovirus, other coronaviruses) was also performed.

The study was performed as a clinical audit using routine collected clinical data and as such is exempt from the need to take specific written informed consent. The study was approved by the local ethics committee (San Matteo Hospital Foundation) on 13th March 2020. The results of this study are reported according to the STrengthening the Reporting of OBservational studies in Epidemiology (STROBE) recommendations [26]. 


\section{Statistical analysis}

Given the observational nature of the study, sample size was not calculated a priori. A descriptive statistical analysis was performed for clinical features, and data were expressed as number of total and/or percentage, mean and standard deviation (SD), or median and range when appropriate. When variables were not available for some patients, these were excluded for percentage calculation. Comparison amongst groups at univariable analysis was performed by the Wilcoxon matched-pairs sign rank test. Spearman correlation coefficient was calculated for relevant laboratory parameters, together with its $95 \%$ confidence interval (95\% CI). For all correlations, patients with a known history of chronic liver disease and those taking anticoagulants were excluded. Also, patients with a history of type 2 diabetes mellitus were excluded when considering urine ketones. Univariable and bivariable Cox regression models were fitted. Hazards ratios (HR) and 95\% CI were computed. Kaplan Meier event-free survival was computed and plotted for patients who had altered liver function tests versus those who had normal ranges. For the analyses of mortality and the composite outcome mortality plus need for intensive care, the role of altered liver function was adjusted, in turn, for the following variables: age $>70$ years, female sex, BMI $>25$, number of comorbidities, $\mathrm{PaO}_{2} / \mathrm{FiO}_{2}<200$ (moderate-severe acute respiratory distress syndrome) [27], $\mathrm{LDH}>450 \mathrm{mU} /$ $\mathrm{ml}$, and neutrophil-to-lymphocyte ratio. Two-tailed $p$ values less than 0.05 were considered statistically significant. The software STATA 16 (StataCorp, College Station, TX) was used for all computations.

\section{Results}

Over the study period, 152 patients were admitted to the internal medicine unit. Of these, 52 patients investigated for clinical suspicious for Covid-19, but with no evidence of SARS-CoV-2 in the collected biological specimens, were excluded from the study. In the remaining 100 cases (median age 70 years old, range 25-97; 79 males; 99 Caucasian and 1 Asian patient), a definite diagnosis of COVID-19 was made on the basis of a SARS-CoV-2-positive nasopharyngeal swab. In four patients, SARS-CoV-2 was detected only through bronchoalveolar lavage. Table 1 summarises the baseline demographic characteristics and lifestyle habits of the whole cohort, while Table 2 shows the most commonly associated conditions. Notably, only a minority (18.6\%) were obese, and most patients were male (79.0\%) and non-smoker $(79.4 \%)$. More than half of the patients $(65.0 \%)$ suffered from essential hypertension. Seven patients suffered from a known chronic liver disease, and their clinical details are reported in Table 3. Child-Pugh score was A6 for patient
Table 1 Demographic and lifestyle habits of the overall cohort of COVID-19 patients

\begin{tabular}{lc}
\hline & Patients $(n=100)$ \\
\hline Age (years), median (range) & $70(25-97)$ \\
Sex, $n(\%)$ & $21(21.0)$ \\
Female & $79(79.0)$ \\
Male & \\
Smoking status, $n(\%)$ & $50 / 63(79.4)$ \\
No smoker/past smoker $(\geq 10$ years) & $7 / 63(11.1)$ \\
Past smoker $(<10$ years $)$ & $4 / 63(6.3)$ \\
Current smoker $(<20$ cigarettes/day) & $2 / 63(3.2)$ \\
Current smoker $(\geq 20$ cigarettes/day) & \\
Alcohol intake, $n(\%)$ & $29 / 61(47.5)$ \\
No alcohol intake & $25 / 61(41.0)$ \\
$<3$ alcohol units/day & $6 / 61(9.8)$ \\
$\geq 3$ alcohol units/day & \\
Body Mass Index, $n(\%)$ & $3 / 59(5.1)$ \\
$<18.5$ & $28 / 59(47.5)$ \\
$18.5-24.9$ & $17 / 59(28.8)$ \\
$25.0-29.9$ & $11 / 59(18.6)$ \\
$30.0-34.9$ & $0 / 59(0.0)$ \\
$\geq 35.0$ &
\end{tabular}

numbers one to five, while it was B7 for patient numbers six and seven. For the sake of homogeneity, these patients were excluded from later analyses. Even if this is just a small series, we noticed that among patients with chronic liver diseases, only one died, while the others had a relatively favourable outcome, and none of these patients had liver decompensation. Table 4 shows the clinical and radiologic features of the 93 remaining patients at the time of admission. Fever $\geq 38.0{ }^{\circ} \mathrm{C}(81.7 \%)$, cough $(58.1 \%)$, and dyspnoea $(49.5 \%)$ were the most common findings, while interstitial pneumonia was the most common chest radiological abnormality (65.6\%). Overall, gastrointestinal symptoms were infrequent (12.9\%), and only a minority of patients presented with diarrhoea (10.8\%). Supplementary Table 1 shows the most relevant laboratory findings at the time of patient admission (none of the patients was treated with antiviral drugs at the time of the evaluation). According to the aforementioned inclusion criteria, liver function test alterations were found in 58/93 patients $(62.4 \%)$. In roughly half of the cases, AST, ALT, and GGT were elevated, while INR was abnormal in $27.7 \%$ of patients at baseline. Also, serum albumin was decreased in $93.5 \%$ of the cases. Supplementary Table 1 reports the most relevant correlations between liver function tests and inflammatory or respiratory parameters. Of note, AST and ALT positively correlated between them and with total bilirubin and GGT, while an inverse correlation between albumin and CRP was noticed. Also, LDH positively correlated with AST, ALT, GGT, and total 
Table 2 Associated conditions in the overall cohort of Covid-19 patients

\begin{tabular}{lc}
\hline & Patients $(n=100)$ \\
\hline At least one associated condition, $n(\%)$ & $84(84.0)$ \\
Chronic ischemic heart disease & $21(21.0)$ \\
Arrhythmia & $20(20.0)$ \\
Valvular heart disease & $11(11.0)$ \\
Essential hypertension & $65(65.0)$ \\
Atherosclerosis & $20(20.0)$ \\
Chronic obstructive pulmonary disease & $7(7.0)$ \\
Asthma & $6(6.0)$ \\
Chronic interstitial pneumonitis & $2(2.0)$ \\
Type 2 diabetes mellitus & $16(16.0)$ \\
Treatment & \\
Diet & $3(3.0)$ \\
Metformin & $6(6.0)$ \\
DPP4-inhibitor (sitagliptin, linagliptin) & $1(1.0)$ \\
Other oral hypoglycaemic agents & $2(2.0)$ \\
Insulin & $7(7.0)$ \\
Chronic liver disease & $7(7.0)$ \\
Non-alcoholic fatty liver disease & $2(3.0)$ \\
HBV-related & $2(2.0)$ \\
HCV-related & $1(1.0)$ \\
Hemochromatosis & $1(1.0)$ \\
Alcohol-related & $1(1.0)$ \\
Thyroid disease & $9(9.0)$ \\
Hyperthyroidism & $2(2.0)$ \\
Hypothyroidism & $7(7.0)$ \\
Chronic kidney disease & $13(13.0)$ \\
Onco-hematologic disease & $6(6.0)$ \\
Neoplastic history & $13(13.0)$ \\
Previous history of neoplastic disease & $4(4.0)$ \\
Active neoplastic disease & $9(9.0)$ \\
\hline & $10(10.0)$ \\
Connective tissue disease & \\
\hline
\end{tabular}

DPP4, dipeptidyl peptidase-4; HBV, hepatitis B virus; HCV, hepatitis $\mathrm{C}$ virus

bilirubin. After exclusion of diabetic patients, no differences regarding the presence of urine ketones between patients with altered liver function tests (20/29 patients, $69 \%$ ) versus those with no alterations ( $9 / 29$ patients, $31.0 \%$; $p=0.336$ ) were noticed.

As shown in Fig. 1, at the last follow-up during hospitalisation (median of 8 days after admission), AST and ALT showed a decreasing trend, while GGT and bilirubin showed an increasing trend, but none of these variations were statistically significant compared to baseline. Instead, INR showed a statistically significant increasing trend at the last follow-up ( $p<0.01$; Fig. 1 ). Only one male patient aged 72 years, who was not treated with antiviral medications and who was being treated with hydroxychloroquine and antibiotics, developed acute liver failure concomitant to acute respiratory distress syndrome (peak ALT 70 IU/l, AST $143 \mathrm{IU} / \mathrm{l}$, GGT $162 \mathrm{IU} / \mathrm{l}$, total bilirubin $15.6 \mathrm{mg} / \mathrm{dl}$, conjugated bilirubin $11.7 \mathrm{mg} / \mathrm{dl}$, INR 1.51, and $\mathrm{PaO}_{2} / \mathrm{FiO}_{2}$ 87) and was transferred to the intensive care unit. In addition, one female patient aged 58 years with a transplanted liver had a very mild disease course (no signs of interstitial pneumonia, or liver function test abnormalities).

Regarding clinical outcomes for the whole cohort, at the time of the writing of the paper, these were available in $71 / 100$ patients $(71.0 \%)$, while 29 patients were still hospitalised, and were considered as censored for the purpose of the analysis. The mean length of stay was $7 \pm 4$ days, 17 (23.9\%) were discharged to home care, 15 (21.1\%) improved and were transferred to a subacute care unit, 14 (19.7\%) worsened and were transferred to the intensive care unit, and $25(35.2 \%)$ died in hospital. Supplementary Fig. 1 shows the unadjusted Kaplan Meier survival estimate and the unadjusted Kaplan Meier event-free survival estimate (death or need for intensive care); no differences were noticed between patients who had liver function test alterations and the others. Regarding mortality only in patients with liver function test alterations versus absence of alterations, no difference was seen between the two groups at bivariable analysis when adjusted for age $>70$ years (HR $1.74,95 \%$ CI $0.73-4.15, p=0.210$ ), female sex (HR 0.93, 95\% CI $0.34-2.54, p=0.884), \mathrm{BMI}>25$ (HR $0.47,95 \% \mathrm{CI}$ 0.14-1.52, $p=0.207$ ), number of comorbidities (HR 1.74, 95\% CI 0.75-4.04, $p=0.194$ ), $\mathrm{PaO}_{2} / \mathrm{FiO}_{2}<200$ (HR 1.72, 95\% CI $0.69-4.25, p=0.241), \mathrm{LDH}>450$ (HR $0.83,95 \%$ CI 0.33-2.09, $p=0.696$ ), and neutrophil-to-lymphocyte ratio (HR $0.87,95 \%$ CI $0.38-2.03, p=0.754$ ). Regarding the combined outcome death or need for intensive care, only $\mathrm{PaO}_{2} / \mathrm{FiO}_{2}<200$ (HR 2.34, 95\% CI 1.07-5.11, $p=0.033$ ) was significantly associated with patients who had altered liver function tests, while the other variables had to statistical significance (data not shown).

\section{Discussion}

We herein described the first Italian, non-Asian, series of patients suffering from COVID-19, admitted to an internal medicine ward, focusing on their clinical picture and liver function impairment. We found that most patients were male, older adults, non-smokers, and non-drinkers. Fever, cough, and dyspnoea were the most common symptoms, while gastrointestinal manifestations were infrequent. After excluding the few cases with a known chronic liver disease, we found that half of the patients presented with raised ALT, AST, or GGT levels. We also observed a single case of acute liver failure in the context of an acute respiratory distress 
Table 3 Characteristics of the seven COVID-19 patients with a known history of chronic liver disease

\begin{tabular}{|c|c|c|c|c|c|c|c|c|}
\hline Patient & Age & Sex & Chronic liver disease & $\begin{array}{l}\text { Other associated condi- } \\
\text { tions }\end{array}$ & Clinical presentation & $\begin{array}{l}\text { Liver function tests at } \\
\text { baseline and follow-up }\end{array}$ & Clinical outcome & Length of stay \\
\hline 1 & 75 & M & Hemochromatosis & Thalassemia minor & $\begin{array}{l}\text { Fever } \\
\text { Interstitial pneumonia }\end{array}$ & $\begin{array}{l}\text { AST }(\mathrm{mU} / \mathrm{ml}): 62 \\
\rightarrow 34 \\
\text { ALT }(\mathrm{mU} / \mathrm{ml}): 36 \\
\quad \rightarrow 20 \\
\text { GGT }(\mathrm{mU} / \mathrm{ml}): 51 \\
\quad \rightarrow 26 \\
\text { Albumin (g/dl): } 3.3 \rightarrow \\
\quad 1.9 \text { INR: } 1.02 \rightarrow 1.42\end{array}$ & ICU & 3 \\
\hline 2 & 60 & M & NAFLD & No & $\begin{array}{l}\text { Cough, fever, dysp- } \\
\text { noea, vomiting } \\
\text { Interstitial pneumonia }\end{array}$ & $\begin{array}{l}\text { AST }(\mathrm{mU} / \mathrm{ml}): 30 \\
\rightarrow 27 \\
\text { ALT }(\mathrm{mU} / \mathrm{ml}): 21 \\
\rightarrow 30 \\
\text { GGT }(\mathrm{mU} / \mathrm{ml}): 60 \\
\quad \rightarrow 90 \\
\text { Albumin }(\mathrm{g} / \mathrm{dl}): 2.8 \\
\rightarrow 3.0 \\
\text { INR: } 1.23 \rightarrow 1.2\end{array}$ & ICU & 2 \\
\hline 3 & 77 & $\mathrm{~F}$ & HCV-related & $\begin{array}{l}\text { Advanced ovarian } \\
\text { cancer }\end{array}$ & $\begin{array}{l}\text { Cough, fever, dyspnoea } \\
\text { Bilateral chest consoli- } \\
\text { dations }\end{array}$ & $\begin{array}{l}\text { AST }(\mathrm{mU} / \mathrm{ml}): 14 \\
\quad \rightarrow 20 \\
\text { ALT }(\mathrm{mU} / \mathrm{ml}): 9 \rightarrow 12 \\
\text { GGT }(\mathrm{mU} / \mathrm{ml}): 43 \\
\quad \rightarrow 42 \\
\text { Albumin }(\mathrm{g} / \mathrm{dl}): 3.5 \\
\quad \rightarrow 3.5 \\
\text { INR: } 1.11 \rightarrow 1.32\end{array}$ & Deceased & 5 \\
\hline 4 & 68 & M & HBV-related & $\begin{array}{l}\text { Valvular heart disease, } \\
\text { essential hyperten- } \\
\text { sion, chronic kidney } \\
\text { disease, atheroscle- } \\
\text { rosis }\end{array}$ & $\begin{array}{l}\text { Cough, fever, and pro- } \\
\text { gressive dyspnoea } \\
\text { Interstitial pneumonia }\end{array}$ & $\begin{array}{l}\text { AST }(\mathrm{mU} / \mathrm{ml}): 16 \\
\quad \rightarrow 11 \\
\text { ALT }(\mathrm{mU} / \mathrm{ml}): 11 \\
\quad \rightarrow 21 \\
\text { GGT }(\mathrm{mU} / \mathrm{ml}): 29 \\
\quad \rightarrow 48 \\
\text { Albumin }(\mathrm{g} / \mathrm{dl}): 3.6 \rightarrow \\
\quad 3.2 \text { INR: } 1.11 \rightarrow 1.52\end{array}$ & Still hospitalised & 14 \\
\hline 5 & 51 & M & NAFLD & $\begin{array}{l}\text { Essential hypertension, } \\
\text { atherosclerosis, type } \\
2 \text { diabetes mellitus }\end{array}$ & $\begin{array}{l}\text { Cough, fever } \\
\text { Interstitial pneumonia }\end{array}$ & $\begin{array}{l}\text { AST (mU/ml): } 49 \\
\quad \rightarrow 41 \\
\text { ALT (mU/ml): } 35 \\
\quad \rightarrow 39 \\
\text { GGT }(\mathrm{mU} / \mathrm{ml}): 181 \\
\quad \rightarrow 138 \\
\text { Albumin (g/dl): } 3.3 \\
\quad \rightarrow 3.2 \\
\text { INR: } 1.21 \rightarrow 1.16\end{array}$ & Discharged & 11 \\
\hline 6 & 73 & M & Alcohol-related & $\begin{array}{l}\text { Essential hypertension, } \\
\text { type } 2 \text { diabetes mel- } \\
\text { litus, chronic kidney } \\
\text { disease }\end{array}$ & $\begin{array}{l}\text { Asymptomatic } \\
\text { Normal chest radio- } \\
\text { logical findings }\end{array}$ & $\begin{array}{l}\text { AST }(\mathrm{mU} / \mathrm{ml}): 108 \\
\rightarrow 96 \\
\text { ALT }(\mathrm{mU} / \mathrm{ml}): 29 \\
\rightarrow 25 \\
\text { GGT }(\mathrm{mU} / \mathrm{ml}): 113 \\
\quad \rightarrow 112 \\
\text { Albumin (g/dl): } 1.8 \\
\quad \rightarrow 2.5 \\
\text { INR: } 1.65 \rightarrow 1.4\end{array}$ & Discharged & 7 \\
\hline 7 & 82 & M & NAFLD & $\begin{array}{l}\text { Ischemic heart disease, } \\
\text { essential hyperten- } \\
\text { sion, type } 2 \text { diabetes } \\
\text { mellitus, chronic } \\
\text { kidney disease }\end{array}$ & $\begin{array}{l}\text { Cough, fever } \\
\text { Normal chest radio- } \\
\text { logical findings }\end{array}$ & $\begin{array}{l}\text { AST }(\mathrm{mU} / \mathrm{ml}): 16 \\
\quad \rightarrow 10 \\
\text { ALT }(\mathrm{mU} / \mathrm{ml}): 9 \rightarrow 9 \\
\text { GGT }(\mathrm{mU} / \mathrm{ml}): 6 \rightarrow 11 \\
\text { Albumin }(\mathrm{g} / \mathrm{dl}): 2.7 \rightarrow \\
2.8 \text { INR: } 0.94 \rightarrow 0.99\end{array}$ & Still hospitalised & 8 \\
\hline
\end{tabular}

ALT, alanine aminotransferase; AST, aspartate aminotransferase; GGT, gamma-glutamyl transpeptidase; INR, international normalized ratio; NAFLD, non-alcoholic fatty liver disease; ICU, intensive care unit

syndrome. At last follow-up, liver function tests improved in most cases, but patients who had altered liver function tests, when adjusted for moderate-severe acute respiratory distress syndrome $\left(\mathrm{PaO}_{2} / \mathrm{FiO}_{2}<200\right)$, showed higher mortality and need for intensive care.

This study has indeed some limitations. First, we did not provide a causal effect between COVID-19 and abnormal 
Table 4 Clinical features of the 93 Covid-19 patients, who entered into the study, at the time of hospital admission

Patients $(n=93)$

\begin{tabular}{lc}
\hline Fever, $n(\%)$ & \\
$<38.0{ }^{\circ} \mathrm{C}$ & $5(5.4)$ \\
$\geq 38.0{ }^{\circ} \mathrm{C}$ & $76(81.7)$ \\
Cough, $n(\%)$ & $54(58.1)$ \\
Dyspnoea, $n(\%)$ & $46(49.5)$ \\
Gastrointestinal symptoms, $n(\%)$ & \\
Nausea and/or vomiting & $2(2.2)$ \\
Diarrhoea & $10(10.8)$ \\
Severe abdominal pain & $1(1.1)$ \\
Chest radiological findings, $n(\%)$ & \\
Normal & $3(3.2)$ \\
Unilateral lung consolidations & $12(12.9)$ \\
Bilateral lung consolidations & $17(18.3)$ \\
Interstitial pneumonia & $61(65.6)$
\end{tabular}

liver function tests, as liver specimens were not obtained from these patients. Hence, a direct cytopathic effect caused by the virus could not be ascertained, even if, according to animal models and small case series, other respiratory tract viruses were shown to have a direct cytopathic effect in the liver [28, 29]. Given the retrospective, real-life nature of the study, we could not establish whether other confounding factors played a role (e.g., previous intake of medications, other undiagnosed liver diseases). Also, the sample size of the study is rather small, thus the generalisability of our results is limited. Nonetheless, we have herein presented the clinical picture, laboratory data, and health outcomes of a cohort of mostly Caucasian patients suffering from COVID-19, focusing on liver function alterations. Also, a major strength of our series, is that only few patients suffered from overt obesity, and only few patients were active alcohol drinkers and smokers. This setting gave us the opportunity to report data regarding liver impairment in patients in whom the prevalence of unhealthy lifestyle habits was very low.

The baseline characteristics and outcomes of a large cohort of Italian patients admitted to the intensive care units in Lombardy have recently been described [30]. Our setting - that of internal medicine-provides a totally different picture of the disease, as patients admitted here had a moderate-to-severe disease, with no need for mechanic intubation at baseline, but who were also treated with continuous positive airway pressure in some cases. Hence, a wide variety of patients, in terms of age, sex, comorbidities, and COVID-19 severity have been included. Most patients were referred not only from the local A\&E
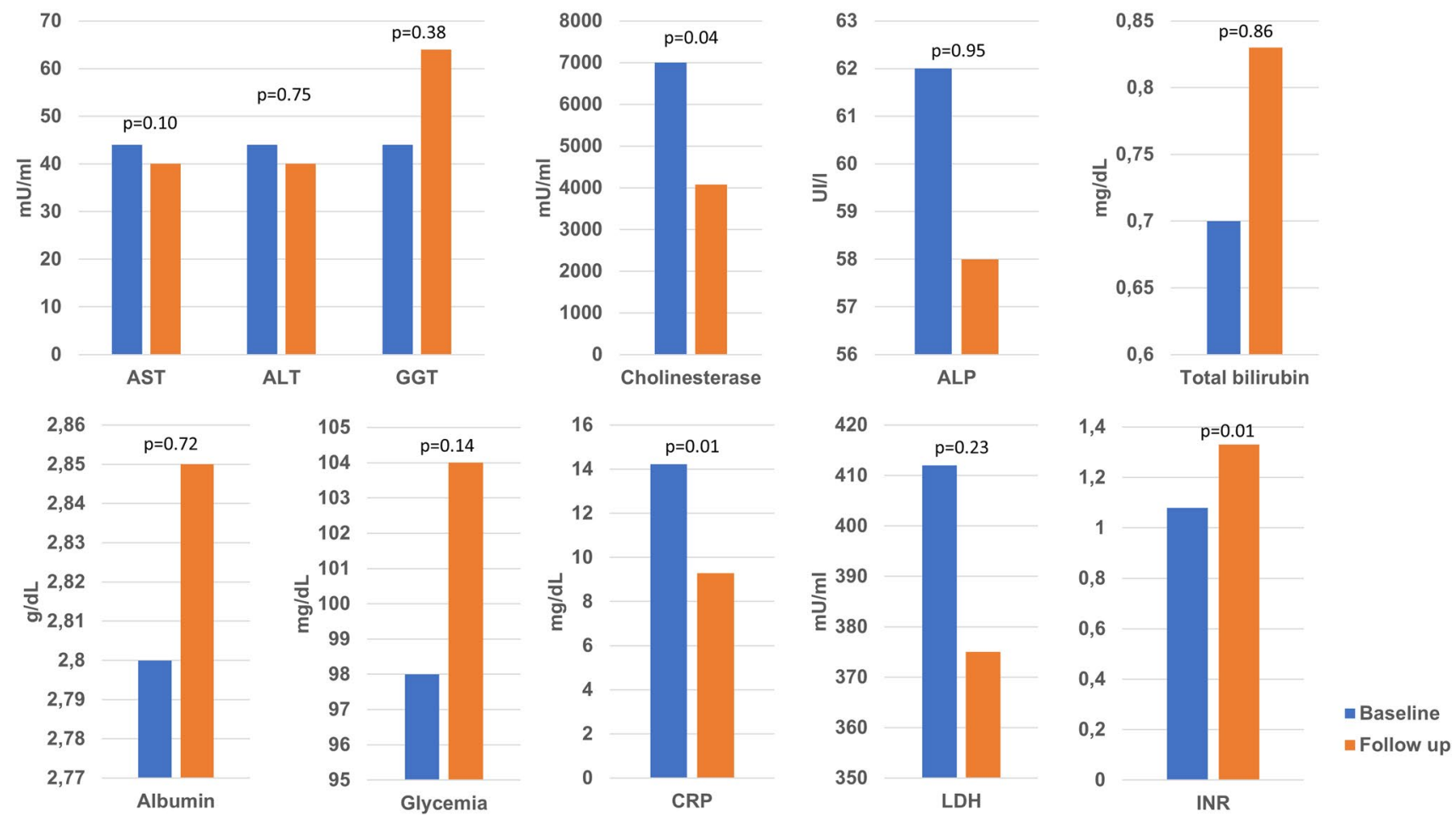

Fig. 1 Comparison of medians of blood tests indicative of abnormal liver function at hospital admission (baseline) and at last follow-up. Wilcoxon test was performed to evaluate statistical significance. ALT, alanine aminotransferase; ALP, alkaline phosphatase; AST, aspartate

aminotransferase; CRP, C reactive protein; GGT, gamma-glutamyl transpeptidase; INR, international normalised ratio; LDH, lactate dehydrogenase 
Department, but also from other hospital specialty wards not dedicated to the treatment of COVID-19, and patients referred to our unit were neither too compromised to need immediate access to intensive care unit nor had a mild disease not requiring hospitalisation.

According to preliminary data, the expression level and expression pattern of the ACE2 gene, encoding for angiotensin-converting enzyme-2, are different between East Asian and other populations, and this may justify a different susceptibility or response to COVID-19 in patients of different ethnicities [31]. East Asian populations have a higher expression of ACE2, and a few cases of acute liver failure have been reported [9, 15-20]. In our series, only one patient, with no history of chronic liver disease developed acute liver failure, but in this case, it was associated with severe respiratory failure. Also, data regarding COVID-19 in liver transplanted patients are scant, and we have here reported the case of one patient who had a very mild disease with no liver involvement.

The impact of COVID-19 in patients with chronic liver disease is still largely unknown. In our series, only few had a history of liver disease, and we did not notice a worse outcome in these patients, or liver decompensation. However, the small sample size does not allow us to draw any firm conclusion. We can assume that liver function test alterations in our patients were actually associated with the acute COVID-19 disease, rather than a pre-existing liver condition, especially considering the low prevalence of obesity and alcohol drinkers. Indeed, COVID-19-induced pneumonia certainly caused hypoxia and inflammation ("reactive" hepatitis, as described in a previous series of patients with SARS) [32], that may justify, at least partially, the biochemical alterations. This assumption is supported by the evidence that a positive correlation between LDH and transaminases was noticed, as well as a negative correlation between cholinesterase and $\mathrm{PaO}_{2} / \mathrm{FiO}_{2}$, and CRP and albumin. At last follow-up, only INR showed an increasing trend, and this might be due to different reasons, including prolonged fasting, prolonged active inflammation, and use of medications, including antibiotics.

Most patients included in our series suffered from multimorbidity. In turn, multimorbidity is a well-established risk factor for polypharmacy [33, 34], and this might be responsible for increased liver toxicity due to drug interactions with COVID-19-related treatments. Zhang et al. have already reported that liver impairment in COVID-19 patients could be drug related [15]. Moreover, a number of drugs that have been used for the treatment of COVID-19 and its related complications, such as hydroxychloroquine, antiviral drugs, and antibiotics, can be likely responsible for hepatotoxicity [19]. Finally, some of our patients suffered from non-alcoholic fatty liver disease that can sensitize the liver for hepatotoxicants, such as acetaminophen, but we excluded them from the final analyses.

To conclude, from a clinical point of view, our data certainly underlie the importance of monitoring liver function in hospitalised COVID-19 patients, not only for the possible risk of developing acute liver failure (1\% in our series) and its implications (e.g., limit the use of potentially toxic medications, strict patient monitoring), but also for stratifying patients who could benefit from early access to the intensive care unit. This is crucial, considering that the pressure put by COVID-19 epidemic in Italy has almost led the healthcare system to collapse [3], and a fair allocation and utilisation of medical resources is a compelling need [35-37]. Considering our results, in an internal medicine setting, we would suggest monitoring liver function tests in all COVID-19 patients, being aware that in case of worsening of respiratory function, they could benefit from early transfer to the intensive care unit, before the onset of a manifest moderate-severe acute respiratory distress syndrome $\left(\mathrm{PaO}_{2} / \mathrm{FiO}_{2}<200\right)$. We, therefore, envisage that future, prospective studies will focus on the impact of liver impairment in patients with COVID19 to strengthen our results, and to further explore the outcomes of patients with chronic liver diseases.

Acknowledgements Open access funding provided by Universit $\tilde{A}$ degli Studi di Pavia within the CRUI-CARE Agreement. Dr. Marco Vincenzo Lenti is grateful to University of Pavia and for supporting his research projects. We thank all the internists, resident physicians, and all healthcare professionals who are currently facing the COVID19 epidemic at the Internal Medicine Unit of San Matteo Hospital Foundation.

Internal Medicine COVID-19 Team: Gaetano Bergamaschi, Giampiera Bertolino, Silvia Codega, Filippo Costanzo, Roberto Cresci, Giuseppe Derosa, Francesco Falaschi, Carmine Iadarola, Elisabetta Lovati, Pietro Carlo Lucotti, Alessandra Martignoni, Amedeo Mugellini, Chiara Muggia, Patrizia Noris, Elisabetta Pagani, Ilaria Palumbo, Alessandro Pecci, Tiziano Perrone, Carla Pieresca, Paola Stefania Preti, Mariaconcetta Russo, Carmelo Sgarlata, Luisa Siciliani, Andrea Staniscia, Francesca Torello Vjera, Giovanna Achilli, Andrea Agostinelli, Valentina Antoci, Alessia Ballesio, Francesco Banfi, Chiara Barteselli, Irene Benedetti, Michele Brattoli, Francesca Calabretta, Ginevra Cambiè, Roberta Canta, Federico Conca, Luigi Coppola, Elisa Maria Cremonte, Gabriele Croce, Virginia Del Rio, Francesco Di Terlizzi, Maria Giovanna Ferrari, Sara Ferrari, Anna Fiengo, Tommaso Forni, Giulia Freddi, Chiara Frigerio, Federica Fumoso, Alessandra Fusco, Margherita Gabba, Matteo Garolfi, Antonella Gentile, Giulia Gori, Giacomo Grandi, Paolo Grimaldi, Alice Lampugnani, Francesco Lapia, Federica Lepore, Gianluca Lettieri, Jacopo Mambella, Chiara Mercanti, Francesco Mordà, Alba Nardone, Luca Pace, Lucia Padovini, Alessandro Parodi, Lavinia Pitotti, Margherita Reduzzi, Giovanni Rigano, Giorgio Rotola, Umberto Sabatini, Lucia Salvi, Giovanni Santacroce, Jessica Savioli, Simone Soriano, Carmine Spataro, Debora Stefani.

Author contributions All authors significantly participated in the drafting of the manuscript or critical revision of the manuscript for important intellectual content and provided approval of the final submitted version. Individual contributions are as follows: ADS, MVL, and FBA designed and coordinated the study, interpreted data and wrote the manuscript. CK did statistical analyses and reviewed the manuscript. FB detected coronavirus in biologic specimens. All the other authors 
followed up patients, locally collected data, and reviewed the paper for final approval. ADS, GRC, MP, CK, and MVL, reviewed the paper and made final critical revision for important intellectual contents.

Funding This research was not directly funded.

\section{Compliance with ethical standards}

Conflict of interest The authors declare that they have no conflict of interest.

Ethical approval The study was performed as a clinical audit using routine collected clinical data. The study was approved by the local ethics committee (San Matteo Hospital Foundation) on March 13th 2020.

Human and animal rights statement All procedures performed in the study were in accordance with the ethical standards of the institutional and/or national research committee and with the 1964 Helsinki Declaration and its later amendments or comparable ethical standards

Informed consent The study was performed as a clinical audit using routine collected clinical data in an anonymised format, and as such is exempt from the need to take specific written informed consent.

Open Access This article is licensed under a Creative Commons Attribution 4.0 International License, which permits use, sharing, adaptation, distribution and reproduction in any medium or format, as long as you give appropriate credit to the original author(s) and the source, provide a link to the Creative Commons licence, and indicate if changes were made. The images or other third party material in this article are included in the article's Creative Commons licence, unless indicated otherwise in a credit line to the material. If material is not included in the article's Creative Commons licence and your intended use is not permitted by statutory regulation or exceeds the permitted use, you will need to obtain permission directly from the copyright holder. To view a copy of this licence, visit http://creativecommons.org/licenses/by/4.0/.

\section{References}

1. Zhu N, Zhang D, Wang W et al (2020) A novel coronavirus from patients with pneumonia in China, 2019. N Engl J Med 382:727-733

2. Guan WJ, Ni ZY, Hu Y et al (2020) Clinical characteristics of coronavirus disease 2019 in China. N Engl J Med 382:1708-1720

3. Remuzzi A, Remuzzi G (2020) COVID-19 and Italy: what next? Lancet 395:1225-1228

4. https://www.salute.gov.it/portale/nuovocoronavirus/ dettaglioConten utiNu ovoCoronavirus.jsp?lingua=itali ano $\&$ id $=5351 \&$ area $=$ nuovoCoronavirus $\&$ menu $=$ vuoto. Accessed 28 Apr 2020

5. https://www.who.int/emergencies/diseases/novel-coronaviru s-2019. Accessed 16 Apr 2020

6. Song JY, Yun JG, Noh JY, Cheong HJ, Kim WJ (2020) Covid-19 in South Korea-challenges of subclinical manifestations. N Engl J Med 382:1858-1859

7. Chen N, Zhou M, Dong X et al (2020) Epidemiological and clinical characteristics of 99 cases of 2019 novel coronavirus pneumonia in Wuhan, China: a descriptive study. Lancet 395:507-513

8. Li LQ, Huang T, Wang YQ et al (2020) 2019 novel coronavirus patients' clinical characteristics, discharge rate, and fatality rate of meta-analysis. J Med Virol 92:577-583
9. Chen $\mathrm{T}, \mathrm{Wu} \mathrm{D}$, Chen $\mathrm{H}$ et al (2020) Clinical characteristics of 113 deceased patients with coronavirus disease 2019: retrospective study. BMJ (Epub ahead of print)

10. Wang Z, Yang B, Li Q, Wen L, Zhang R (2020) Clinical features of 69 cases with coronavirus disease 2019 in Wuhan, China. Clin Infect Dis (Epub ahead of print)

11. Jia HP, Look DC, Shi L et al (2005) ACE2 receptor expression and severe acute respiratory syndrome coronavirus infection depend on differentiation of human airway epithelia. J Virol 79:14614-14621

12. Gurwitz D (2020) Angiotensin receptor blockers as tentative SARS-CoV-2 therapeutics. Drug Dev Res (Epub ahed of print)

13. Liu Z, Xiao X, Wei X et al (2020) Composition and divergence of coronavirus spike proteins and host ACE2 receptors predict potential intermediate hosts of SARS-CoV-2. J Med Virol 92:595-601

14. Jin X, Lian JS, Hu JH et al (2020) Epidemiological, clinical and virological characteristics of 74 cases of coronavirus-infected disease 2019 (COVID-19) with gastrointestinal symptoms. Gut 69:1002-1009

15. Zhang C, Shi L, Wang FS (2020) Liver injury in COVID-19: management and challenges. Lancet Gastroenterol Hepatol 5:428-430

16. Huang C, Wang Y, Li X et al (2020) Clinical features of patients infected with 2019 novel coronavirus in Wuhan, China. Lancet 395:497-506

17. Wang $\mathrm{D}, \mathrm{Hu} \mathrm{B}, \mathrm{Hu} \mathrm{C}$ et al (2020) Clinical characteristics of 138 hospitalised patients with 2019 novel coronavirus-infected pneumonia in Wuhan, China. JAMA 323:1061-1069

18. Shi H, Han X, Jiang $N$ et al (2020) Radiological findings from 81 patients with COVID-19 pneumonia in Wuhan, China: a descriptive study. Lancet Infect Dis 20:425-434

19. Xu X-W, Wu X-X, Jiang X-G et al (2020) Clinical findings in a group of patients infected with the 2019 novel coronavirus (SARS-Cov-2) outside of Wuhan, China: retrospective case series. BMJ (Epub ahead of print)

20. Yang X, Yu Y, Xu J et al (2020) Clinical course and outcomes of critically ill patients with SARS-CoV-2 pneumonia in Wuhan, China: a single-centered, retrospective, observational study. Lancet Respir Med 8:475-481

21. Lenti MV, Corazza GR, Di Sabatino A (2020) Carving out a place for internal medicine during COVID-19 epidemic in Italy. J Intern Med (Epub ahead of print)

22. Asperges E, Novati S, Muzzi A et al (2020) Rapid response to COVID-19 outbreak in Northern Italy: how to convert a classic infectious disease ward into a COVID-19 response centre. J Hosp Infect 105:477-479

23. Akilli NB, Yortanlı M, Mutlu H et al (2014) Prognostic importance of neutrophil-lymphocyte ratio in critically ill patients: short- and long-term outcomes. Am J Emerg Med 32:1476-1480

24. WHO (2020) Novel coronavirus - China. https://www.hoint/csr/ don/12-january-2020-novel-coronavirus-china/en/. Accessed 19 Jan 2020

25. Corman VM, Landt O, Kaiser M et al (2020) Detection of 2019 novel coronavirus (2019-nCoV) by real-time RT-PCR. Euro Surveill 25:2000045

26. von Elm E, Altman DG, Egger M et al (2007) The Strengthening the Reporting of Observational Studies in Epidemiology (STROBE) statement: guidelines for reporting observational studies. Ann Intern Med 147:573-577

27. Villar J, Pérez-Méndez L, Blanco J et al (2013) A universal definition of ARDS: the $\mathrm{PaO}_{2} / \mathrm{FiO}_{2}$ ratio under a standard ventilatory setting - a prospective, multicenter validation study. Intensive Care Med 39:583-592

28. Zhang S, Hu B, Xu J, Ren Q, Wang L, Wang S (2019) Influenza A virus infection induces liver injury in mice. Microb Pathog $137: 103736$ 
29. Schütte A, Ciesek S, Wedemeyer H, Lange CM (2019) Influenza virus infection as precipitating event of acute-on-chronic liver failure. J Hepatol 70:797-799

30. Grasselli G, Zangrillo A, Zanella A et al (2020) Baseline characteristics and outcomes of 1591 patients infected with SARSCoV-2 admitted to ICUs of the Lombardy Region, Italy. JAMA 323:1574-1581

31. Cao Y, Li L, Feng Z et al (2020) Comparative genetic analysis of the novel coronavirus (2019-nCoV/SARS-CoV-2) receptor ACE2 in different populations. Cell Discov (Epub ahead of print)

32. Chan HL, Kwan AC, To KF et al (2005) Clinical significance of hepatic derangement in severe acute respiratory syndrome. World J Gastroenterol 11:2148-2153

33. Mannucci PM, Nobili A, Investigators REPOSI (2014) Multimorbidity and polypharmacy in the elderly: lessons from REPOSI. Intern Emerg Med 9:723-734
34. Corazza GR, Formagnana P, Lenti MV (2019) Bringing complexity into clinical practice: an internistic approach. Eur J Intern Med 61:9-14

35. Rosenbaum L (2020) Facing Covid-19 in Italy-ethics, logistics, and therapeutics on the epidemic's front line. N Engl J Med 382:1873-1875

36. Emanuel EJ, Persad G, Upshur R et al (2020) Fair allocation of scarce medical resources in the time of Covid-19. N Engl J Med 382:2049-2055

37. Truog RD, Mitchell C, Daley GQ (2020) The toughest triage-allocating ventilators in a pandemic. N Engl J Med 382:1973-1975

Publisher's Note Springer Nature remains neutral with regard to jurisdictional claims in published maps and institutional affiliations.

\section{Affiliations}

\section{Marco Vincenzo Lenti ${ }^{1}$. Federica Borrelli de Andreis ${ }^{1}$. Ivan Pellegrino ${ }^{1}$. Catherine Klersy ${ }^{2}$. Stefania Merli ${ }^{1}$. Emanuela Miceli ${ }^{1}$ - Nicola Aronico ${ }^{1}$ - Caterina Mengoli ${ }^{1} \cdot$ Michele Di Stefano $^{1}$ - Sara Cococcia ${ }^{1}$. \\ Giovanni Santacroce ${ }^{1}$. Simone Soriano ${ }^{1}$. Federica Melazzini ${ }^{1}$ - Mariangela Delliponti ${ }^{1}$ - Fausto Baldanti ${ }^{3}$. Antonio Triarico $^{4}$. Gino Roberto Corazza ${ }^{1}$ - Massimo Pinzani ${ }^{5}$. Antonio Di Sabatino ${ }^{1,6}{ }^{(1)}$ on behalf of the Internal Medicine Covid-19 Team}

1 Department of Internal Medicine, San Matteo Hospital Foundation, University of Pavia, Pavia, Italy

2 Biometry and Clinical Epidemiology Service, San Matteo Hospital Foundation, Pavia, Italy

3 Molecular Virology Unit, Microbiology and Virology Department, San Matteo Hospital Foundation, Pavia, Italy

4 Chief Medical Direction, San Matteo Hospital Foundation, Pavia, Italy
5 UCL Institute for Liver and Digestive Health and Sheila Sherlock Liver Unit, Royal Free Hospital and UCL, London, UK

6 Clinica Medica, Fondazione IRCCS Policlinico San Matteo, Università di Pavia, Viale Golgi 19, 27100 Pavia, Italy 